\title{
Investigation of the spin-forbidden process in thymine
}

\author{
Mihajlo R. Etinski \\ University of Belgrade, Faculty of Physical Chemistry, Belgrade, Serbia
}

\begin{abstract}
The intersystem crossing rate from the lowest singlet to the lowest triplet state of thymine was studied by means of $a b$ initio methods. The rate was calculated employing the timedependent approach based on the correlation function. The normal modes of the singlet and triplet electronic states are related by the Duschinsky transformation, i.e. by rotation and translation. The correlation function was calculated using the Condon approximation for the spin-orbit matrix element and harmonic approximation for the nuclear motion. The intersystem crossing rate strongly depends on the singlet-triplet adiabatic energy gap and on the normal mode mixing.
\end{abstract}

Keywords: excited states, intersystem crossing, correlation function, thymine.

\section{SCIENTIFIC PAPER}

UDC 547.853:544

Hem. Ind. 66 (2) 165-170 (2012)

doi: 10.2298/HEMIND110924079E

Available online at the Journal website: http://www.ache.org.rs/HI/

Theoretical chemistry contributes a lot to the insight into molecular structure and reactivity. In order to rationalize elementary photochemical processes, mechanistic viewpoint is introduced. It includes motion of the nuclei on the ground and excited potential energy surfaces (PESs) and characterization of the points on PESs such as minima, saddle points and PESs intersections [1].

The ground electronic state of organic molecules is usually a closed-shell singlet. Singlet excited states are created after photoexcitation. They are metastable and decay to the ground state through radiative or nonradiative processes. These processes can be intermediate steps in photochemical reactions. One of the nonradiative processes is an intersystem crossing. It involves a transition between electronic states of the different spin multiplicity, i.e., singlet to triplet electronic states in organic molecules. It is a forbidden process in nonrelativistic quantum chemistry but becomes allowed when coupling between spin and orbital momenta is included. Triplet states are significant in organic photochemistry because they can be highly reactive [1]. Due to this, it is important to know the rates of their formation. Rates of intersystem crossing are essentially properties of chromophores. The knowledge of rates is useful in designing molecules that can serve as photolabile protected biological compounds [2] or are involved in photodynamic therapy [3].

There is evidence that triplet states of nucleic acids are involved in the formation of nucleic acids photoproducts that are mutagenic and carcinogenic for skin cells [4-8]. The most frequent photoreaction of nucleic

Correspondence: M.R. Etinski, Faculty of Physical Chemistry, University of Belgrade, Studentski Trg 12-16, P. O. Box 47, 11158 Belgrade, Serbia.

E-mail: etinski@ffh.bg.ac.rs

Paper received: 24 September, 2011

Paper accepted: 4 October, 2011 acids is an intrastrand pyrimidine dimerization. This reaction covalently links two pyrimidine basis and yields mostly cyclobutane pyrimidine dimmer (CPD) and a small amount pyrimidine (6-4) pyrimidone photoproduct and related Dewar-valence isomers. Thymine is a pyrimidine base that has the highest yield of the photoproducts. Therefore, it is important to investigate the triplet state formation in thymine in order to understand the molecular origin of UV-induced carcinogenesis and mutagenesis of nucleic acids.

Gas phase allows investigation of intrinsic properties of thymine - the properties that are independent of solvation. Time-resolved spectroscopic experiments showed that thymine in the gas phase, after initial photoexcitation, relaxes on femtosecond, picosecond and nanosecond timescales. For several hundred nanoseconds it remains trapped in the long-lived electronic state [9-13]. This state is a non-fluorescent (dark) state. It could be the lowest singlet excited state $S_{1}\left({ }^{1} n \pi^{*}\right)$, the lowest triplet $\mathrm{T}_{1}\left({ }^{3} \pi \pi^{*}\right)$ or the hot ground state. Etinski et al., based on the quantum chemical calculations, argued that the dark state is the lowest triplet state $T_{1}\left({ }^{3} \pi \pi^{*}\right)$ and that it is formed from the lowest singlet excited state $S_{1}\left({ }^{1} n \pi^{*}\right)$ [14]. Recently, Kunitski et al. performed a time-resolved spectroscopic experiment in the gas phase in order to assign the dark state of thymine [13]. They measured a transient IR spectrum of the dark state in the $\mathrm{OH} / \mathrm{NH}$ stretch region. Their results confirmed the findings of Etinski et al.

Solvation can modify adiabatic energy gaps because excited states can have different polarizabilities. Etinski and Marian found that hydration could significantly shift electronic excited states of the pyrimidine basis $[15,16]$. They found that the $S_{1}\left({ }^{1} n \pi^{*}\right)$ state in thymine was blue-shifted by $0.51 \mathrm{eV}$ while the $\mathrm{T}_{1}\left({ }^{3} \pi \pi^{*}\right)$ state was blue-shifted by $0.09 \mathrm{eV}$. Thus, it is of importance to examine in what manner the adiabatic energy gap modifies the ISC rate. 
The goal of this work is to establish how the ISC rate in thymine from the $S_{1}\left({ }^{1} n \pi^{*}\right)$ to the $T_{1}\left({ }^{3} \pi \pi^{*}\right)$ state depends on the electronic structure parameter such as the Duschinsky rotation (mixing) of the normal modes and adiabatic energy gap.

The paper is organized as follows: in the next section I shall explain how the ISC rates can be calculated using the correlation function approach. Then, details of the rate calculations, the results and discussion will be presented. Finally, conclusions will be given.

\section{THE CORRELATION FUNCTION METHOD}

ISC rates are evaluated using the perturbation approach. The perturbation expansion is limited to the first-order, i.e., the Golden rule approximation. This is justified because all atoms in thymine are light so that spin-orbit coupling $\hat{H}_{\text {so }}$ could be treated as a perturbation.

The correlation function method presents a timedependent approach to the rate calculation. The correlation function is calculated in time-domain and the rate is obtained by integration of the correlation function [18]. In this case, the evaluation of enormously large number of the Franck-Condon integrals is avoided. This is particularly important for large molecules and large adiabatic energy gaps.

In this work, we are interested in the evaluation of the rate from the initial singlet vibronic state to the final triplet states. Rates are calculated assuming the statistical limit, i.e., a high density of the final states. Large number of normal modes creates a quasi-continuum of triplet vibronic states allowing an irreversible transfer of the initial population to the triplet electronic state.

As zero-order states for the perturbation calculation, pure spin Born-Oppenheimer states $\left|S_{a},\left\{v_{a j}\right\}\right\rangle$ and $\left\{T_{b}^{\alpha},\left\{v_{b k}\right\}\right\rangle$ were used. Here $S_{a}$ is a singlet electronic state, $t_{b}^{\alpha}$ is an $\alpha$ fine-structure component of a triplet electronic state, and $\left\{v_{a j}\right\}$ and $\left\{v_{b k}\right\}$ are vibrational states related to the $S_{a}$ and $T_{b}^{\alpha}$ states. In the body-fixed rotating molecular coordinate system, the electronic potential energies of the singlet and triplet states in the vicinity of their minima can be diagonalized by introducing normal-mode coordinates $\left\{Q_{s i}\right\}$ and $\left\{Q_{T i}\right\}$. Generally, normal modes of the triplet state are displaced and rotated relatively to the singlet state normal modes. The transformation between them is the Duschinsky transformation [18]:

$Q_{T_{i}}=\sum_{j} J_{i j} Q_{S_{j}}+D_{i}$ where $J$ is the Duschinsky rotation matrix and $D$ is the displacement vector.

The rate from the initially populated vibronic state $\left|S_{a},\left\{v_{a j}\right\}\right\rangle$ to triplet vibronic states $\left|T_{b}^{\alpha},\left\{v_{b k}\right\}\right\rangle$ is given by:

$k_{I S C}=2 \pi \sum_{k}\left|\left\langle S_{a},\left\{v_{a j}\right\}\left|\hat{H}_{S O}\right| T_{b}^{\alpha},\left\{v_{b k}\right\}\right\rangle\right|^{2} \delta\left(E_{a j}-E_{b k}\right)$

Spin-orbit matrix elements (SOMEs) generally depends weakly on the normal mode coordinates. They can be expanded using the Taylor expansion about the initial geometry:

$$
\begin{aligned}
& \left\langle S_{a},\left\{v_{a j}\right\}\left|\hat{H}_{S O}\right| T_{b}^{\alpha},\left\{v_{b k}\right\}\right\rangle=\left\langle v_{a j}\left|\left\langle S_{a}\left|\hat{H}_{S O}\right| T_{b}^{\alpha}\right\rangle\right| Q_{0} \mid v_{b k}\right\rangle+ \\
& +\left\langle v_{a j}\left|\sum_{i} \frac{\partial\left\langle S_{a}\left|\hat{H}_{S O}\right| T_{b}^{\alpha}\right\rangle}{\partial Q_{i}}\right| Q_{0} Q_{i} \mid v_{b k}\right\rangle+\ldots
\end{aligned}
$$

Keeping only the first term represents the Condon approximation and contributes to the direct spin-orbit coupling. The second and higher order terms represent Hertzberg-Teller expansion and they contribute to the vibronic spin-orbit coupling. In this work, only the direct spin-orbit coupling will be considered because the transition from the $S_{1}\left(n \pi^{*}\right)$ to the $T_{1}\left(\pi \pi^{*}\right)$ in thymine is orbitally allowed - the first term in the Taylor expansion of the SOMEs is significantly larger than the higher terms.

Assuming only a direct spin-orbit coupling, the ISC rate from the initial vibronic level, is given by:

$$
k_{I S C}=2 \pi\left|\left\langle S_{a}\left|\hat{H}_{S O}\right| T_{b}^{\alpha}\right\rangle\right|^{2} \sum_{k}\left|\left\langle v_{a j} \mid v_{b k}\right\rangle\right|^{2} \delta\left(E_{a j}-E_{b k}\right)
$$

In this case, the calculation of the rate is reduced to the calculation of the electronic part $\left|\left\langle S_{a}\left|\hat{H}_{s o}\right| T_{b}^{\alpha}\right\rangle\right|$ and the vibrational part, i.e., the Franck-Condon integrals $\left\langle v_{a j} \mid v_{b k}\right\rangle$.

Transforming the expression (4) into the Heisenberg picture, we obtain:

$k_{I S C}^{c o r r}=\int_{-\infty}^{\infty}\left\langle v_{a j}\left|\hat{H}_{S O}(0) \hat{H}_{S O}(t)\right| v_{a j}\right\rangle \mathrm{d} t$

where $\hat{H}_{S O}(t)=e^{i \hat{H}_{0} t} \hat{H}_{S O} e^{-i \hat{H}_{0} t}$ is the spin-orbit operator in the Heisenberg picture. $\hat{H}_{0}=\hat{H}_{S}+\hat{H}_{T}$ is the zero-order Hamiltonian that includes vibrational motion on the singlet and triplet potential surfaces. Etinski et al. [17] showed that the previous expression can be evaluated in the following way:

$k_{I S C}^{c o r r}=\left|\left\langle S_{a}\left|\hat{H}_{S O}\right| T_{b}^{\alpha}\right\rangle\right|^{2} \int_{-\infty}^{\infty} F_{c o r r}(t) \mathrm{d} t$

where

$$
\begin{aligned}
F_{\text {corr }}(t) & =2^{N / 2} \sqrt{\frac{\operatorname{det}\left(S_{T}^{-1} \Omega_{S} \Omega_{T}\right)}{\operatorname{det}\left(J^{T} \Omega_{T} B_{T} J+\Omega_{S}\right) \operatorname{det}\left(J^{T} \Omega_{T} B_{T}{ }^{-1} J+\Omega_{S}\right)}} \\
& \times \exp \left(D^{T}\left(\Omega_{T} B_{T} J\left(J^{T} \Omega_{T} B_{T} J+\Omega_{S}\right)^{-1} J \Omega_{T} B_{T}-\Omega_{T} B_{T}\right) D\right) e^{i t\left(\Delta E_{S T}+1 / 2 T r \Omega_{S}\right)}
\end{aligned}
$$


and $\Omega, S, B$ are diagonal matrices with elements $(\Omega)_{i i}=\omega_{i},(S)_{i i}=\sinh \left(i \omega_{i} t\right),(B)_{i i}=\tanh \left(i \omega_{i} t / 2\right), \omega_{i}$ is a normal mode frequency, indexes $S$ and $T$ label normal modes of the singlet and triplet electronic states and superscript $T$ indicates the transposition of a matrix. $\Delta E_{S T}$ is an adiabatic energy between singlet and triplet electronic states.

The calculation of the correlation function involves only matrix multiplication, matrix inversion and calculation of a determinant. The correlation function has an odd imaginary part and an even real part. Therefore, the evaluation of the rate is reduced to the calculation of the real part of the correlation function for a positive time interval. Input parameters needed for the calculation of the rate are normal mode frequencies of the singlet and triplet electronic states, the displacement vector, the Duschinsky matrix, the adiabatic energy gap and the spin-orbit matrix element.

\section{DETAILS OF THE INTERSYSTEM CROSSING RATE CALCULATIONS}

In this work we will use electronic structure data obtained in the work of Etinski et al. [14]. They optimized the $S_{1}\left({ }^{1} n \pi^{*}\right)$ and $T_{1}\left({ }^{3} \pi \pi^{*}\right)$ excited states of thymine using the coupled-cluster with approximative doubles (CC2) method. This method represents an approximation to the coupled-cluster singles and doubles (CCSD) method where the singles equations are retained in the original form and the doubles equations are truncated to the first order in the fluctuating potential [19]. The basis set was Dunning's cc-pVDZ basis set (C, N, O, 9s4p1d/3s2p1d; H, 4s1p/2s1p) [20,21].

The excited state geometries were optimized without symmetry constraints. The molecular geometry of the $S_{1}$ state was planar while the $T_{1}$ state was butterfly-shaped. Since there is a large difference in the $S_{1}$ and $\mathrm{T}_{1}$ molecular geometries the parameters from the Duschinsky relation, the displacement and mixing of the normal modes are large. Figure 1 presents the absolute displacement of the $T_{1}$ state normal modes relative to the $S_{1}$ state normal mode in dimensionless harmonic oscillator coordinates. There are several low-frequency modes that are highly displaced. These modes are vibronically active and they considerably contribute to the rate. However, the normal modes with small displacement can also contribute to the rate. Sando et al. [22] showed that when the Duschinsky mixing is present, modes with small displacement cannot be ignored in the calculation of the nonradiative rate, particularly when their number is large.

Figure 2 presents the Duschinsky matrix for the transition between the $S_{1}$ and $T_{1}$ states of thymine. Almost all normal modes of the triplet states have more than one component in the basis of the singlet state normal modes. Also, some high-frequency modes are mixed with the low-frequency modes. Due to this it is important to include all normal modes into calculations.

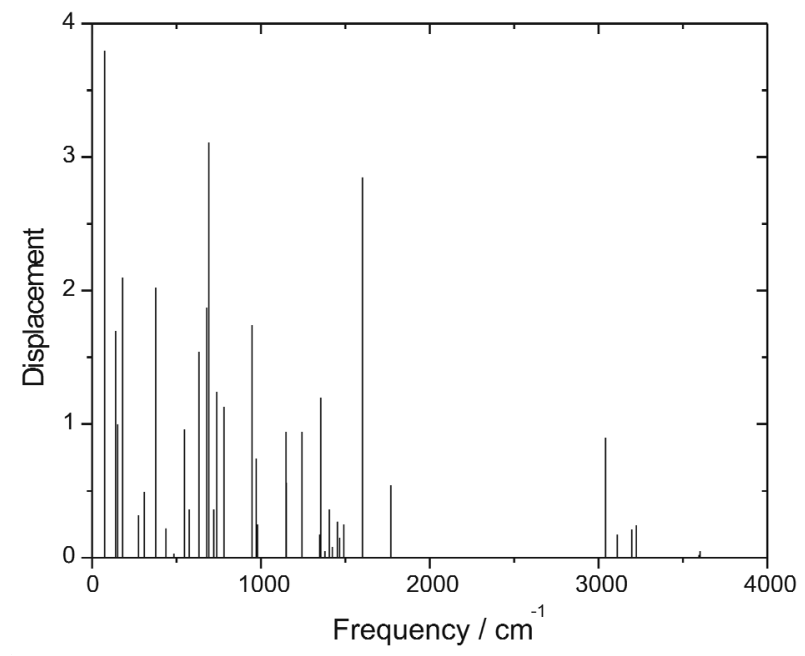

Figure 1. Absolute displacement of the $T_{1}$ state normal modes relative to the $S_{1}$ state normal mode in dimensionless harmonic oscillator coordinates.

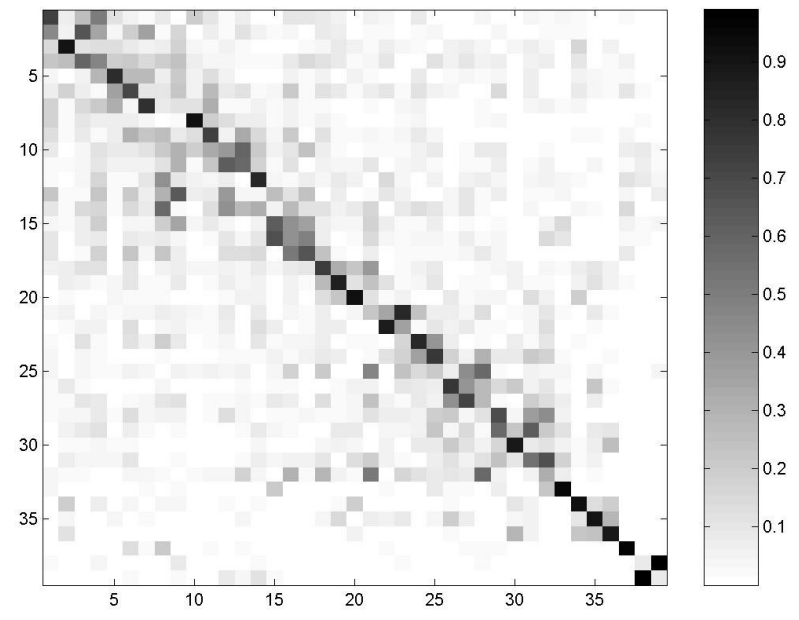

Figure 2. Duschinsky matrix related to the transition between the $S_{1}$ and $T_{1}$ states of thymine. In order to visualize the normal mode mixing, absolute values of the matrix elements are shown.

The adiabatic energy gap between $\mathrm{S}_{1}$ and $\mathrm{T}_{1}$ electronic states of thymine obtained at the CC2/cc-pVDZ level is $6652 \mathrm{~cm}^{-1}$. SOMEs were calculated using SPOCK program based on the DFT/MRCl electronic structure method [23]. SPOCK employs a one-center mean-field approximation to the Breit-Pauli Hamiltonian [24]. SOMEs were calculated at the $S_{1}$ optimized minimum. The sum of the squares of all SOMEs between the $S_{1}$ state and all fine-structure components of the $T_{1}$ state is $2319 \mathrm{~cm}^{-2}$. All rates that will be presented in this work are a sum of the three rates from the $S_{1}$ state to the three fine-structure components of the $T_{1}$ state. 
The correlation function was calculated for the first 10 fs using 1000 points. We found that the rate is very robust to the density of points needed for the integration of the correlation function.

\section{RESULTS AND DISCUSSION}

The time dependence in the expression (5) can give a physically more appealing picture based on the wavepacket time-correlation function. After slight arrangement we obtain:

$$
k_{I S C}^{c o r r}=\left.\left|\left\langle S_{a}\left|\hat{H}_{S O}\right| T_{b}^{\alpha}\right\rangle\right|\right|_{-\infty} ^{\infty}\left\langle v_{a j}\left|e^{i t \hat{H}_{S}} e^{-i t \hat{H}_{T}}\right| v_{a j}\right\rangle e^{i t \Delta E_{S T}} \mathrm{~d} t
$$

The correlation function can be understood as an autocorrelation function of the initial wavepacket on the singlet potential surface and its projection on the triplet potential surface. As the initial wave packet is nonstationary on the triplet potential surface, it moves. Therefore, the ISC rate is directly related to the overlap between the initial wave packet on the singlet potential surface and the moving wavepacket on the triplet potential surface. The wavepacket autocorrelation function decays due to multimode motion. The recurrence time of various normal modes are different doing the autocorrelation function to vanish after sometime. In this case, the correlation function will become zero.

Figure 3 presents the correlation functions calculated for various adiabatic energy gaps when the Duschinsky mixing is included and excluded from the calculations. The adiabatic energy gap varied from 1000 to $10000 \mathrm{~cm}^{-1}$ in steps of $1000 \mathrm{~cm}^{-1}$. The correlation function calculated with the smallest adiabatic energy gap has the largest oscillation amplitude. The increase of the adiabatic energy gap decreases the oscillation amplitude. This can be explained in light of the previous discussion on the wavepacket autocorrelation function. The negative amplitude of the correlation function comes from the return of the wavepacket on the triplet potential surface. As the adiabatic energy gap increases, it takes more time for wavepacket to return to the Franck-Condon zone so that the correlation function amplitude decreases and shifts to larger times.

It is interesting that in the absence of the Duschinsky mixing between the normal modes, the correlation function significantly increases the oscillation amplitude. This means that normal modes are strongly mixed as it was concluded from Figure 2. The mixing of the normal modes makes the triplet potential surface more different form the singlet potential surface and therefore the overlap of the singlet and triplet surface wavepackets decreases.

Figure 4 presents the ISC rates calculated from the correlation functions presented in Figure 3. The simple rule called energy gap law assumes that the rate of a non-radiative transition between two electronic states becomes larger if the energy difference between the states decreases [25]. In our case, where the potential surfaces are strongly displaced, the rate increases with the increase of the energy gap.

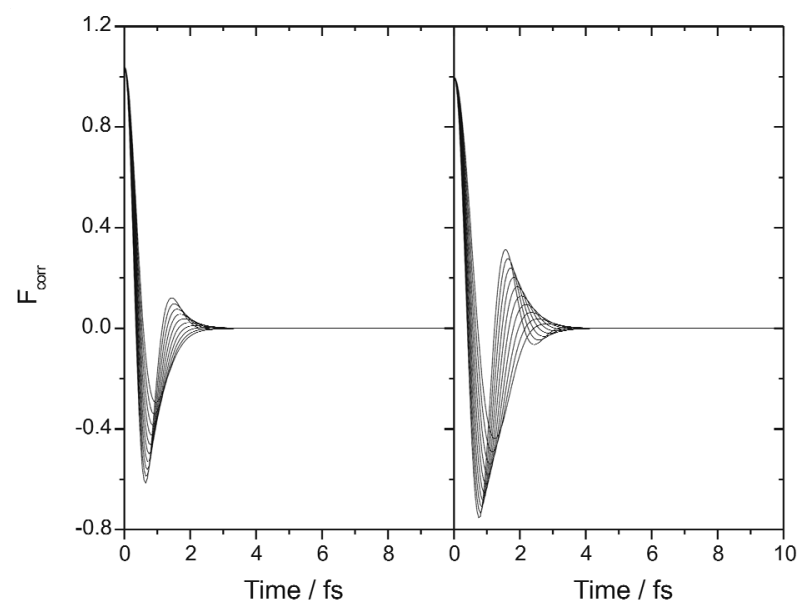

Figure 3. The correlation functions calculated with (left) and without (right) the Duschinsky mixing for various adiabatic energy gaps. The adiabatic energy gap varied from 1000 to $10000 \mathrm{~cm}^{-1}$ in steps of $1000 \mathrm{~cm}^{-1}$.

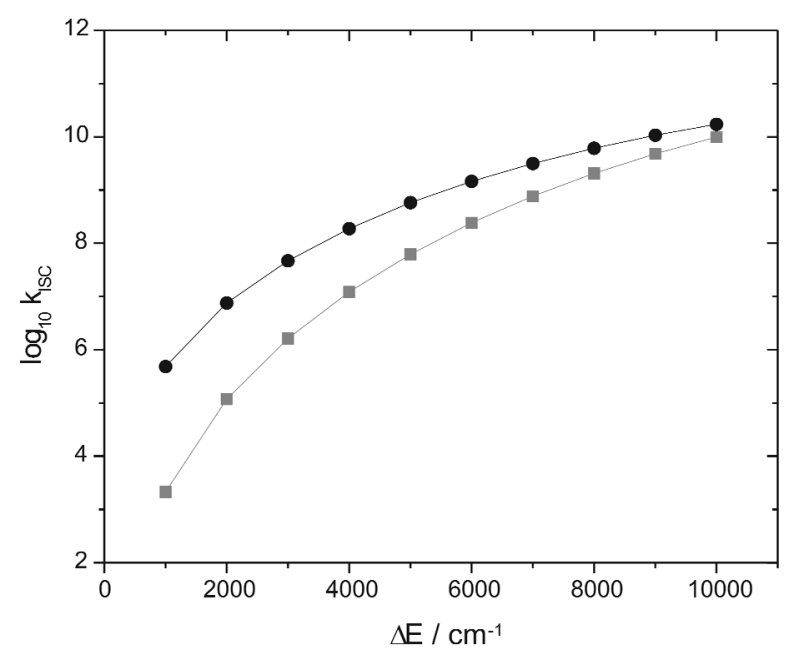

Figure 4. Dependence of the logarithm of the ISC rate calculated with (black) and without (gray) the Duschinsky mixing for various adiabatic energy gaps. The adiabatic energy gap varied from 1000 to $10000 \mathrm{~cm}^{-1}$ in steps of $1000 \mathrm{~cm}^{-1}$.

The rates are highly dependent on the adiabatic energy gap variations. The rate changes six orders of magnitude when the adiabatic energy gap changes from 1000 to $10000 \mathrm{~cm}^{-1}$. This dependence is more pronounced for smaller energy gaps. For larger energy gaps, there is a saturation so that the ISC rates are less sensitive to the adiabatic energy changes. Hence, it is important to know the precise values of the adiabatic 
energy gap for various environments in order to be able to quantitatively calculate the rate constant. In the gas phase, the adiabatic energy gap is $6652 \mathrm{~cm}^{-1}$ and hence the rate is $2.45 \times 10^{9} \mathrm{~s}^{-1}$.

Lin and coworkers showed on the model composing of two normal modes that the ratio of the rates calculated with and without the Dushinsky mixing for various degree of mixing can be fairly complicated [26]. In our case, the rate obtained with the Duschinsky mixing is usually an order of magnitude larger than without the Duschinsky mixing. Hence, in thymine the Duschinsky mixing plays the key role for the rate calculation.

\section{CONCLUSIONS}

We have studied the intersystem crossing rate from the lowest singlet to the lowest triplet state in thymine. The rate was calculated employing the correlation function approach. Since the normal modes of the singlet and triplet potential energy surface were different, the Duschinsky transformation between the normal modes was introduced. It maps the normal modes of the singlet state to normal mode of the triplet state by translation and rotation.

Parameters needed for the rate evaluation are taken from quantum chemical $a b$ initio calculations. The correlation function was related to the wavepacket autocorrelation function. Since the initial wavepacket is non-stationary on the triplet potential surface, it evolves. The overlap between the wavepackets on the singlet and triplet potential surfaces determines the correlation function. It decays due to multimode motion. The increase of the adiabatic energy gap makes the correlation function amplitude to decrease and to shift to larger times.

We found that the rate strongly depends on the singlet-triplet adiabatic energy gap and on the Duschinsky mixing. This means that these parameters are important for a quantitative evaluation of the intersystem crossing rate in thymine.

\section{Acknowledgement}

The author acknowledges the Ministry of Education and Science of the Republic of Serbia for the financial support (Contract No. 172040).

\section{REFERENCES}

[1] N.J. Turro, J.C. Scaiano, V. Ramamurthy, Modern Molecular Photochemistry of Organic Molecules, $1^{\text {st }}$ ed., University Science Books, California, 2010.

[2] K. Shaper, M. Etinski, T. Fleig, Theoretical investigation of the excited states of 2-nitrobenzyl and 4,5-methylendioxy-2-nitrobenzyl caging groups, Photoch. Photobiol. 85 (2009) 1075-1081.
[3] J. Tatchen, N. Gilka, C.M. Marian, Intersystem crossing driven by vibronic spin-orbit coupling: A case study on psoralen, Phys. Chem. Chem. Phys. 9 (2007) 5209-5221.

[4] W.-M. Kwok, C. Ma, D.L. Phillips, A Doorway, State leads to photostability or triplet photodamage in thymine DNA, J. Am. Chem. Soc. 130 (2008) 5131-5139.

[5] Y.-J. Ai, R.-Z. Liao, S.-F. Chen, Y. Luo, W.-H. Fang, Theoretical studies on photoisomerizations of (6-4) and dewar photolesions in DNA, J. Phys. Chem. B 114 (2010) 14096-14102.

[6] R.B. Zhang, L.A. Eriksson, A Triplet mechanism for the formation of cyclobutane pyrimidine dimers in UV-irradiated DNA, J. Phys. Chem. B 110 (2006) 7556-7562.

[7] Z.B. Yang, R.B. Zhang, L.A. Eriksson, A triplet mechanism for the formation of thyminethymine (6-4) dimers in UVirradiated DNA, Phys. Chem. Chem. Phys. 13 (2011) 8961-8966.

[8] C. Curutchet, A.A. Voityuk, Triplet-triplet energy transfer in DNA: A process that occurs on the nanosecond timescale, Angew. Chem. Int. Ed. 50 (2011) 1820-1822.

[9] Y. He, C. Wu, W. Kong, Decay pathways of thymine and methyl-substituted uracil and thymine in the gas phase, J. Phys. Chem. A 107 (2003) 5145-5148.

[10] Y. He, C. Wu, W. Kong, Photophysics of methyl-substituted uracils and thymines and their water complexes in the gas phase, J. Phys. Chem., A 108 (2004) 943-949.

[11] M. Busker, M. Nispel, T. Häber, K. Kleinermanns, M. Etinski, T. Fleig, Electronic and vibrational spectroscopy of 1-methylthymine and its water clusters: The dark state survives hydration, Chem. Phys. Chem. 9 (2008) 1570-1577 .

[12] J. González-Vázquez, L. González, E. Samoylova, T. Schultz, Thymine relaxation after UV irradiation: the role of tautomerization and pi sigma* states, Phys. Chem. Chem. Phys. 11 (2009) 3927-3934.

[13] M. Kunitski, Y. Nosenko, B. Brutschy, On the nature of the long-lived "dark" state of isolated 1-methylthymine, Chem.Phys.Chem. 12 (2011) 2024-2030.

[14] M. Etinski, T. Fleig, C. M. Marian, Intersystem crossing and characterization of dark states in the pyrimidine nucleobases uracil, thymine, and 1-methylthymine, J. Phys. Chem., A 113 (2009) 11809-11816.

[15] M. Etinski, C.M. Marian, Ab initio investigation of the methylation and hydration effects on the electronic spectra of uracil and thymine, Phys. Chem. Chem. Phys. 12 (2010) 4915-4923

[16] M. Etinski, C.M. Marian, Overruling the energy gap law: fast triplet formation in 6-azauracil, Phys. Chem. Chem. Phys. 12 (2010) 15665-15671.

[17] M. Etinski, J. Tatchen, C.M. Marian, Time-dependent approaches for the calculation of intersystem crossing rates, J. Chem. Phys. 134 (2011) 154105-154105-9.

[18] F. Duschinsky, Zur Deutung der Elektronenspektren mehratomiger Molekule I. Uber des Franck-CondonPrinzip, Acta Physicochim. URSS 7 (1937) 551-566.

[19] O. Christiansen, H. Koch, P. Jørgensen, The second-order approximate coupled cluster singles and doubles model CC2, Chem. Phys. Lett. 243 (1995) 409-418. 
[20] T.H. Dunning, Gaussian basis sets for use in correlated molecular calculations. I. The atoms boron through neon and hydrogen, J. Chem. Phys. 90 (1989) 1007$-1024$.

[21] R.A. Kendall, T.H.J. Dunning, R.J. Harrison, Electron affinities of the first-row atoms revisited. Systematic basis sets and wave functions, J. Chem. Phys. 96 (1992) 6796$-6807$.

[22] G.M. Sando, K.G. Spears, J.T. Hupp, P.T. Ruhoff, Large electron transfer rate effects from the duschinsky mixing of vibrations, J. Phys. Chem., A 105 (2001) 5317-5325 .

[23] M. Kleinschmidt, J. Tatchen, C.M. Marian, Spin-orbit coupling of DFT/MRCI wavefunctions: Method, test cal- culations, and application to thiophene, J. Comp. Chem. 23 (2002) 824-833.

[24] B.A. Hess, C.M. Marian, U. Wahlgren, O. Gropen, A mean-field spin-orbit method applicable to correlated wavefunctions, Chem. Phys. Lett. 251 (1996) 365-371.

[25] R. Englman, J. Jortner, The energy gap law for radiationless transitions in large molecules, Mol. Phys. 18 (1970) 145-164.

[26] M. Hayashi, A.M. Mebel, K.K. Liang, S.H. Lin, Ab initio calculations of radiationless transitions between excited and ground singlet electronic states of ethylene, J. Chem. Phys. 108 (1998) 2044-2055.

\section{IZVOD}

\section{ISTRAŽIVANJE SPINSKI ZABRANJENOG PROCESA U TIMINU}

\section{Mihajlo R. Etinski}

Univerzitet u Beogradu, Fakultet za fizičku hemiju, Beograd, Srbija

(Naučni rad)

Najčešća fotohemijska reakcija nukleinskih kiselina je dimerizacija pirimidinskih baza. Timin je pirimidinska baza koja ima najveći prinos dimerizacije. Istraživanja su pokazala da je početni korak dimirizacije timina stvaranje tripletnih stanja timina. U ovom radu je proučavana konstanta brzine spinski zabranjenog intersistemskog prelaza između najnižeg pobuđenog singletnog elektronskog stanja i najnižeg triplet elektronskog stanja timina pomoću $a b$ initio metoda teorijske hemije. Konstanta brzine intersistemskog prelaza je računata koristeći Fermijevo zlatno pravilo iz pertubacione teorije. Ona se može predstaviti kao integral vremenske korelacione funkcije. Normalni modovi singletnog i tripletog elektronskog stanja su povezani transformacijom Dušinskog, tj. pomoću rotacije i translacije. Korelaciona funkcija je računata podrazumevajući Kondonovu aproksimaciju za spin-orbitni matrični element i harmonijsku aproksimaciju potencijala za kretanje jezgara. Vremenska zavisnost korelacione funkcije je objašnjena razmatrajući autokorelacionu funkciju talasnog paketa, koja predstavlja preklapanje talasnog paketa koji miruje na singletnoj elektronskoj površini i talasnog paketa koji se kreće na tripletnoj elektronskoj površini. Konstanta brzine intersistemskog prelaza se menja šest redova veličine kada se adijabatska energija singletnog-tripletnog procepa menja od 1000 do $10000 \mathrm{~cm}^{-1}$. Takođe, ako se u proračun uzme da su normalni modovi tripletnog stanja samo pomereni ali ne i rotirani u odnosu na normalne modove singletnog stanja, dobijaju se rezultati koji se značajno razlikuju u odnosu na potpune proračune. Zbog toga, da bi se kvalitativno odredila konstanta intersistemskog prelaza u timinu, od velike je važnosti uzeti u proračun potpunu zavisnost između normalnih modova singletnog i tripletnog elektronskog stanja, kao $i$ tačnu vrednost adijabatske elektronske energije.
Ključne reči: Pobuđena stanja • Intersistemski prelazi $\bullet$ Korelaciona funkcija • Timin 